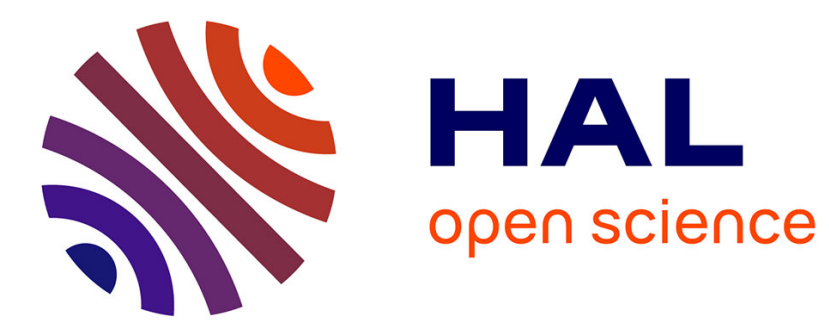

\title{
High temperature corrosion kinetics by a fast X-ray diffraction method applied to nickel
}

\author{
V. Kolarik, M. Juez-Lorenzo, N. Eisenreich, W. Engel
}

\section{To cite this version:}

V. Kolarik, M. Juez-Lorenzo, N. Eisenreich, W. Engel. High temperature corrosion kinetics by a fast X-ray diffraction method applied to nickel. Journal de Physique IV Proceedings, 1993, 03 (C9), pp.C9-447-C9-452. 10.1051/jp4:1993947 . jpa-00252387

\section{HAL Id: jpa-00252387 https://hal.science/jpa-00252387}

Submitted on 1 Jan 1993

HAL is a multi-disciplinary open access archive for the deposit and dissemination of scientific research documents, whether they are published or not. The documents may come from teaching and research institutions in France or abroad, or from public or private research centers.
L'archive ouverte pluridisciplinaire HAL, est destinée au dépôt et à la diffusion de documents scientifiques de niveau recherche, publiés ou non, émanant des établissements d'enseignement et de recherche français ou étrangers, des laboratoires publics ou privés. 


\title{
High temperature corrosion kinetics by a fast X-ray diffraction method applied to nickel
}

\author{
V. Kolarik, M. Juez-Lorenzo, N. Eisenreich and W. Engel
}

Fraunhofer-Institut für Chemische Technologie ICT, Joseph-von-Fraunhofer-Str. 7, 76327 Pfinztal, Germany

\begin{abstract}
Temperature and time resolved X-ray diffraction was used as an in situ method, which allows the determination of kinetic data combined with the identification of the corrosion products. The performance of the method was demonstrated on the high temperature oxidation of nickel in isothermal and non-isothermal experiments. The kinetic parameters were obtained by means of the difference method. The resulting curves show the global changes as a function of time or temperature. These curves were calibrated to the microscopically measured end thickness of the oxide layer yielding the growth of the layer with time $x(t)$ or with temperature $x(T)$, respectively. Calculated curves were fitted to the measured data yielding the kinetic parameters. In the non-isothermal case the temperature dependence of the oxidation rate constant, described by the Arrhenius relation, is obtained in one single experiment.
\end{abstract}

\section{Introduction.}

The development of high temperature resistant alloys requires detailed knowledge of the corrosion reactions $[1,2]$. In many cases in situ information is desirable as phase transitions may occur on cooling. Conventionally high temperature corrosion is studied under isothermal conditions in several experiments at different temperatures in a defined atmosphere. The corrosion products are identified after cooling and the temperature dependence of the oxidation rate constant is usually determined from these series $[2,3]$.

Thermogravimetry (TG) is often applied to obtain non-isothermal experiments in situ. This method, however, monitors only weight changes, but does not identify the structure of the oxide layer.

The combination of an X-ray diffractometer and a high temperature device allows the required in situ investigation of corrosion processes $[4,5]$. Series of diffraction diagrams are recorded with fast detectors during a freely selectable temperature program. A numerical procedure applied to the isothermal or non-isothermal series of diffraction patterns allows the determination of the oxidation rate constants.

The performance of the system was demonstrated on the high temperature oxidation of nickel in a series of isothermal and non-isothermal experiments.

\section{Experimental.}

2.1 MEASURING SYSTEM. - The system consists of an X-ray diffractometer with a high temperature device. Linear and stepwise heating with different steps and heating rates can be selected within a temperature interval of 20 and $1700^{\circ} \mathrm{C}$ as well as isothermal programs. 
On each temperature step or after defined time intervals, diffraction patterns are recorded. Series of up to 300 diffraction patterns are measured during a day. The diffraction patterns are recorded with a position sensitive proportional counter (PSPC), or with a scintillation counter. Especially the PSPC allows a fast scanning of an angular range yielding exposure times of 2 to 3 min per pattern.

2.2 MEASUREMENTS. - Isothermal and non-isothermal experiments were carried out in air with nickel alloy N 201, LC-Ni99 (DIN 17740). The surface of the specimen was polished. The diffraction patterns were recorded with $\mathrm{Cu}$-radiation and a scintillation counter scanning $10 \%$ min from 36 to 76.9 degrees $2 \theta$.

The isothermal experiments were performed at $700,800,900$ and $1000^{\circ} \mathrm{C}$. Non-isothermal series were measured from 100 to $1000^{\circ} \mathrm{C}$ in steps of $15^{\circ} \mathrm{C}$ with an average heating rate of $3^{\circ} \mathrm{C} / \mathrm{min}$.

2.3 Evaluation. - The kinetic evaluation was carried out using the difference method [6], which forms the difference between two patterns. The sum $Y\left(t_{j}\right)$ of the absolute differences between corresponding channels correlates with the changes in the diffraction diagrams.

$$
Y\left(t_{j}\right)=\sum_{i=1}^{n}\left|Y_{i}\left(t_{1}\right)-Y_{i}\left(t_{j}\right)\right|
$$

$j=$ number of the current diagram; $i=$ number of the current channel; $n=$ total number of channels; $t=$ time (in non-isothermal; series temperature).

The difference method can be applied to the whole patterns or to selected intervals containing definite peaks, yielding separate $Y(t)$ curves for the base material and the oxides. The $Y(t)$ curves of the oxides were normalized to 1 and the $Y\left(t_{j}\right)$ values were multiplied by the final thickness of the oxide layer that was measured microscopically. The resulting curve $x_{\mathbf{m}}(t)$ represents the growth of the oxide layer taking into account the increasing absorption in the growing layer.

$$
x_{\mathrm{m}}(t)=f_{\mathrm{c}} \frac{\sin \Theta}{2 \mu}\left(1-\mathrm{e}^{-\frac{2 \mu}{\sin \Theta} x(t)}\right)
$$

$x_{\mathrm{m}}=$ measured curve, $x(t)=$ time law of the scale growth, $\mu=$ absorption coefficient, $2 \Theta=$ diffraction angle, $f_{\mathrm{c}}$ calibration factor.

2.4 ISOTHERMAL KINETICS. - A parabolic time law $x(t)=\sqrt{2 k t}$ is expected for nickel oxidation at high temperatures $[2,7]$ and was inserted into (1). The parabolic oxidation rate constant $k$ is determined directly by a least squares fit.

2.5 NON-ISOTHERMAL KINETICS. - On linear heating the growth of the oxide layer depends on temperature and time. For obtaining the temperature dependence of the parabolic rate constant, the $x(T)$ curve must be described by a function $f=f(T, t)[8]$.

Introducing the heating rate $\alpha=\mathrm{d} T / \mathrm{d} t$ and the Arrhenius equation for the temperature dependence of reaction rates the following description for the temperature dependent growth $x(T)$ of the oxyde scale is obtained: 


$$
x(T)=\sqrt{\frac{2 z}{\alpha} \int \mathrm{e}^{-\frac{E}{R T}} \mathrm{~d} T}
$$

where $E$ is the activation energy, $z$ the preexponential factor, $\alpha$ the heating rate and $R$ the universal gas constant.

The equation (2) is inserted into (1) and a least squares fit procedure yields values for the fit parameters $z$ and $E$.

\section{Results and discussion.}

In all patterns only $\mathrm{Ni}$ and $\mathrm{NiO}$ peaks were observed as expected. The progress of the oxidation can be observed qualitatively in the series of diffraction patterns (Fig. 1). The difference method was applied to the angular regions of the patterns containing peaks of NiO. The resulting curves were calibrated by means of the described procedure.

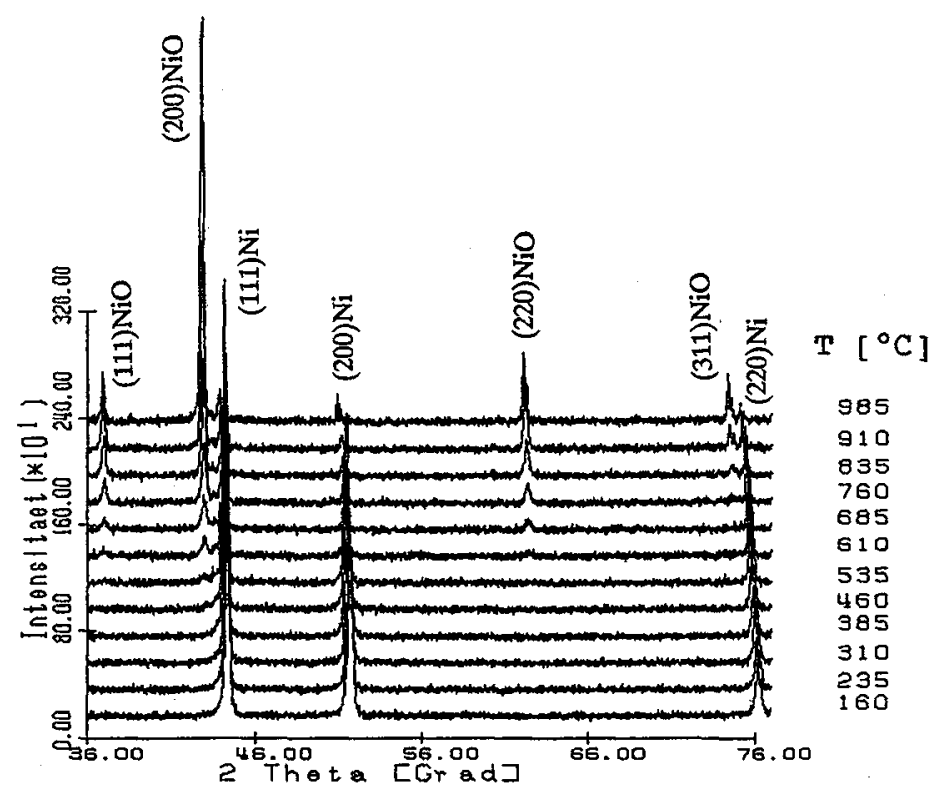

Fig. 1. - Selected patterns from a non-isothermal series.

Mathematical curves including the parabolic time law were fitted to the isothermal $x_{\mathrm{m}}(t)$ curves yielding the parabolic rate constants. Figure 2 shows the measured curve $x_{\mathbf{m}}(t)$ of the $\mathrm{NiO}$ scale at 700 and $800^{\circ} \mathrm{C}$ together with the fitted curves.

In the non-isothermal experiments the fit of a calculated curve to the measured curve yields an activation energy of $E=160 \mathrm{~kJ}$. Figure 3 shows the measured and the calculated $x_{\mathrm{m}}(T)$ curve. Inserting the fitted parameters $z$ and $E$ into the Arrhenius equation the temperature dependence of the parabolic oxidation rate constant was determined. 


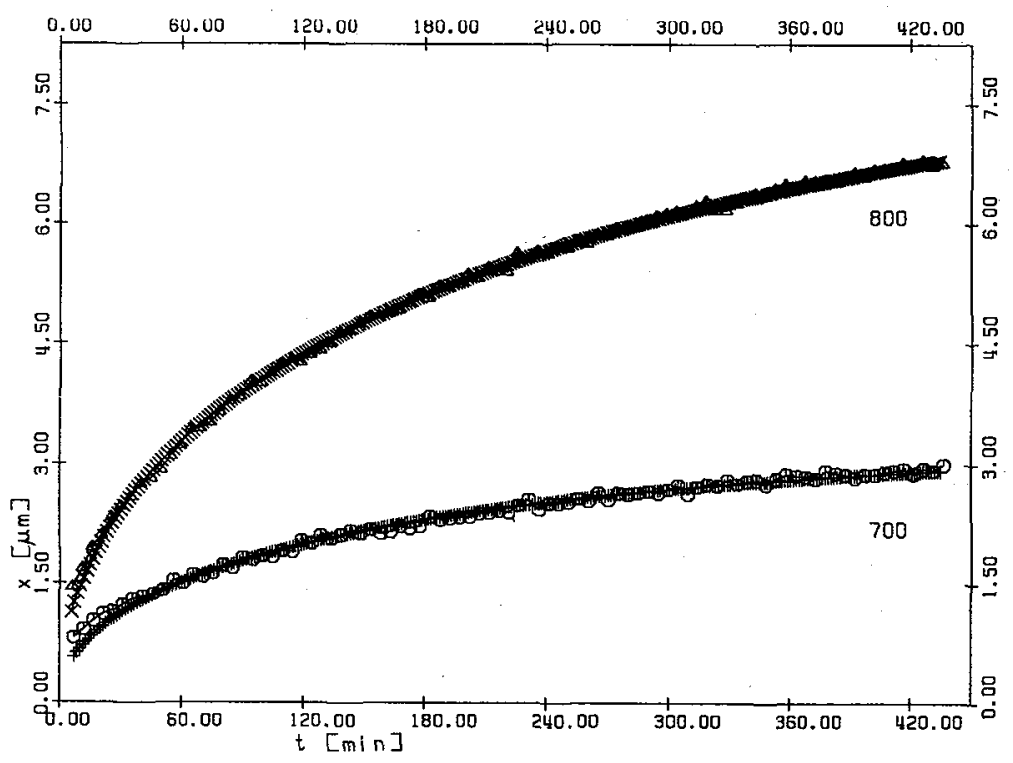

Fig. 2. - Measured and fitted curves $x_{\mathrm{m}}(t)$ at 700 and $800{ }^{\circ} \mathrm{C}$.

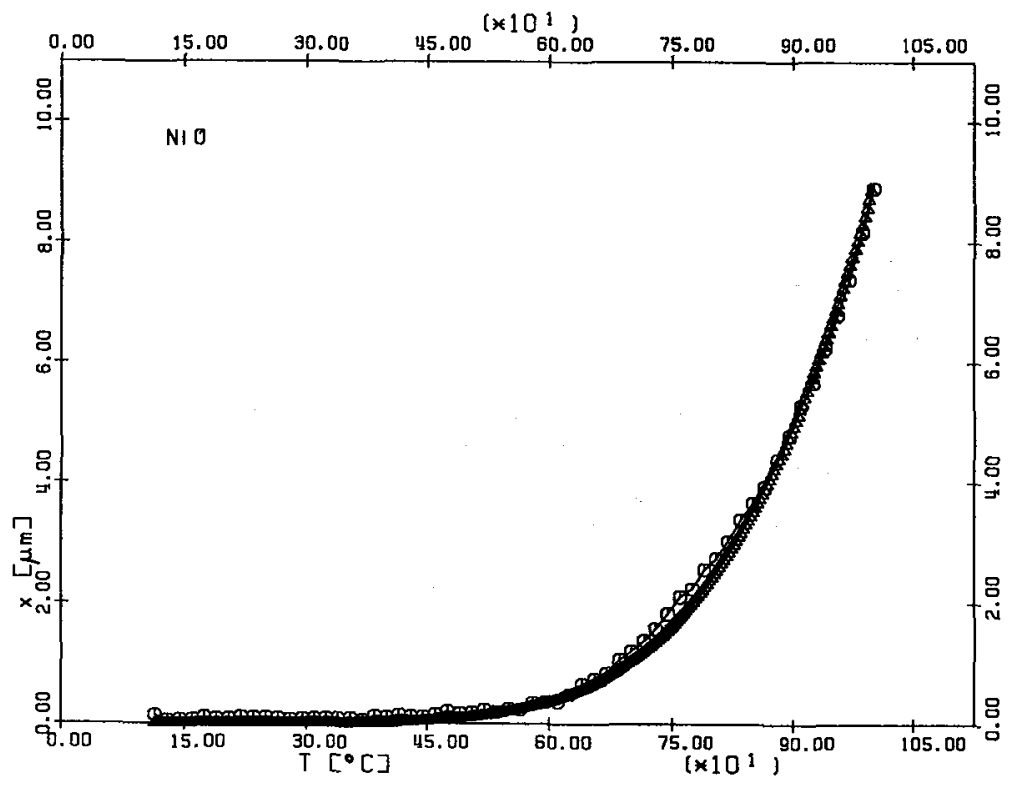

Fig. 3. - Measured and fitted curve $x_{\mathrm{m}}(T)$ on linear heating.

The parabolic rate constants from both the isothermal and non-isothermal series are compared in an Arrhenius-plot (Fig. 4). The results of the isothermal series are given in table 1 . Both measuring conditions, isothermal and non-isothermal, yield coinciding values for the 


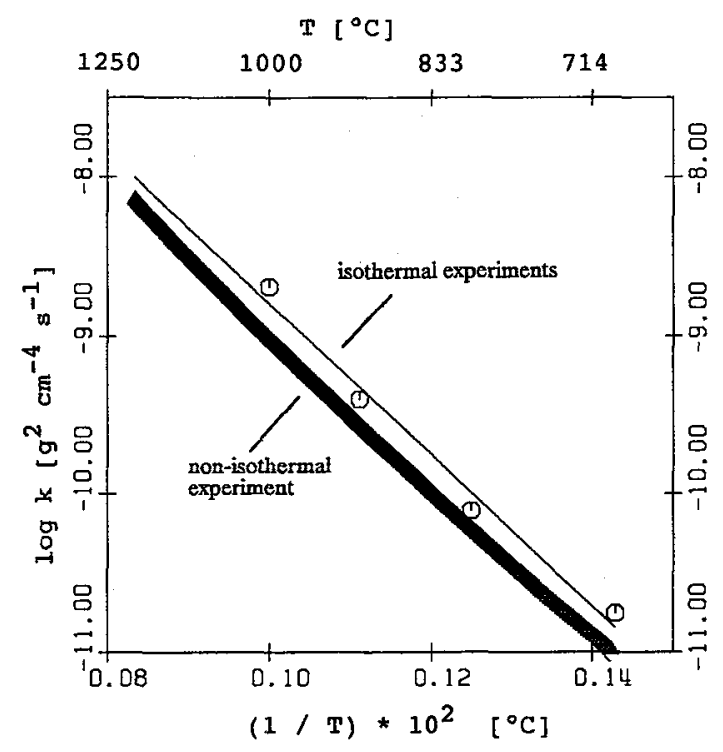

Fig. 4. - Comparison of the results from the isothermal experiments with the non-isothermal measurement.

Table I. - Parabolic rate constants of the isothermal series.

\begin{tabular}{|c|c|}
\hline$T\left[{ }^{\circ} \mathrm{C}\right]$ & $\mathrm{k}\left[\mathrm{g}^{2} \mathrm{~cm}^{-4} \mathrm{~s}^{-1}\right]$ \\
\hline 700 & $1.7 \times 10^{-11}$ \\
\hline 800 & $7.8 \times 10^{-11}$ \\
\hline 900 & $3.9 \times 10^{-10}$ \\
\hline 1000 & $2.1 \times 10^{-9}$ \\
\hline
\end{tabular}

parabolic rate constant.

Repeating the experiments under the same conditions slight variations of the results were observed. Especially in the non-isothermal case lower values for the activation energy were obtained.

The range of the measured values reported for $k$ is rather wide. The values obtained from $\mathrm{X}$-ray diffraction can be compared with the literature values, although they are often higher than the literature data [7, 9-12]. In the present work the samples were exposed short times $(2 \mathrm{~h}$ to $5 \mathrm{~h}$ ) to the high temperature, meanwhile the literature values are obtained from longer experiments (up to $100 \mathrm{~h}$ ). The higher values for $k$ in the initial state are in agreement with the observations reported by $\mathrm{A}$. Atkinson et al. [11].

The growth of an oxide layer can be studied by means of X-ray diffraction only when the whole observed layer is penetrated. The maximum observable thickness of the layer depends on its absorption coefficient $\mu$ at the wavelength of the X-ray tube. Generally it is in the range of 15 to $80 \mu \mathrm{m}$. The X-ray diffraction method allows a detailed investigation of corrosion processes in the initial states due to the possibility to record a diffraction diagram every $4 \mathrm{~min}$, or less. 
The different curves $Y(t)$ and $Y(T)$ give a precise information because the difference method is a very sensitive procedure showing the smallest changes even in peaks that are so small that they hardly can be observed. Fitting the $x_{\mathrm{m}}(t)$ curves only their bends are important for the determination of the rate constant. The errors in the measurements of the end thickness are compensated by a calibration factor in the fit procedure.

\section{Conclusions.}

X-ray diffraction is a suitable method for the investigation of high temperature corrosion and its kinetics. The oxides can be identified in situ and the temperature dependence of the oxidation rate constant can be determined by means of the difference method in series of isothermal experiments or in a single non-isothermal experiment given that there is no phase transition within the studied temperature interval.

\section{References}

[1] Rahmel A., Schwenk W., Korrosion und Korrosionsschutz von Stählen (Verlag Chemie, 1977).

[2] KOFSTAD P., High Temperature Corrosion (Elsevier Applied Science Ltd, 1988).

[3] Otero E., Criado A.J., Hierro P., Pardo A., Baladia M., Corrosion Behaviour of a stainless steel $12 \mathrm{Cr} 1 \mathrm{Mo} 0.3 \mathrm{~V}$ 0.2C at temperatures higher than $973 \mathrm{~K}$, Proc. 22nd Int. Annual Conf. of ICT, Combustion and Reaction Kinetics, 114 (1) (1991).

[4] KolariK V., JUEZ-LOREnZo M., EISEnREICH N., Engel W., High-Temperature Corrosion Kinetics Using a Fast X-ray Diffraction Method; Proc. Ist European Powder Diffraction Conference EPDIC1, Mater. Sci. Forum 79/82 (1991) p.617.

[5] Kolarik V., JUEZ-LORENZO M., EISENREICH N., ENGEL W., Non-Isothermal Kinetics of High Temperature Oxidation Studied by a fast X-ray Diffraction Method.; 5th European Symposium on Thermal Analysis and Calorimetry ESTAC5 (Nice, August 1991).

[6] Eisenreich N., Engel W., J. Appl. Cryst. 16 (1983) 259.

[7] BETTERIDGE W., Nickel and its Alloys, MacDonald and Evans Ltd., Industrial Metals Series, ISBN 0712109471 (1977).

[8] EISENREICH N., J. Thermal Anal. 19 (1980) 289.

[9] DECHEMA Corrosion Handbook Vol. 4, D. Behrens Eds, VCH.

[10] Smeltzer W.W., Young D.J., Prog. Solid State Chem. 10 (I) (1975) 17-54.

[11] Atkinson A., TaYlor R.I., Hughes A.E., Philos. Mag. A 45 (1982) 823-833.

[12] Atkinson A., Rev. Mod. Phys. 57 (1985) 437-470. 